\title{
AIDS LAW PROJECT OF SOUTH AFRICA HONOURED
}

On 12 September 2003 in Montreal, the AIDS Law Project (ALP), a pioneering organisation that helps combat HIV/AIDS by protecting the rights of the millions affected by the disease in South Africa, was the recipient of the 2003 'Award for Action on HIV/AIDS and Human Rights' from the Canadian HIVIAIDS Legal Network and Human Rights Watch.

The AIDS Law Project gives the world a model for combating AIDS by fighting stigma, discrimination, sexual violence and other gender-related abuses that fuel the epidemic, said Ralf Jürgens, executive director of the Canadian HIV/AIDS Legal Network.

ALP has also been on the frontlines of the battle for the right of people with AIDS in South Africa to have access to antiretroviral drugs. 'ALP has steadfastly fought the irrationality of the South African government's stance on drugs for AIDS, and it has helped create a movement that will eventually win this struggle', said Jürgens.

The AIDS Law Project co-founded the Treatment Action Campaign (TAC), chaired by Zackie Achmat, a former ALP director. ALP and TAC led a coalition that took the South African government to court in 2002 , leading to a ruling that requires the provision of antiretroviral drugs to pregnant women for the prevention of mother-to-child HIV transmission. TAC and ALP are also leading players in the grassroots movement that led to the recent announcement by the South African government that it would roll out an antiretroviral treatment plan after years of resisting the very idea of treatment for AIDS.

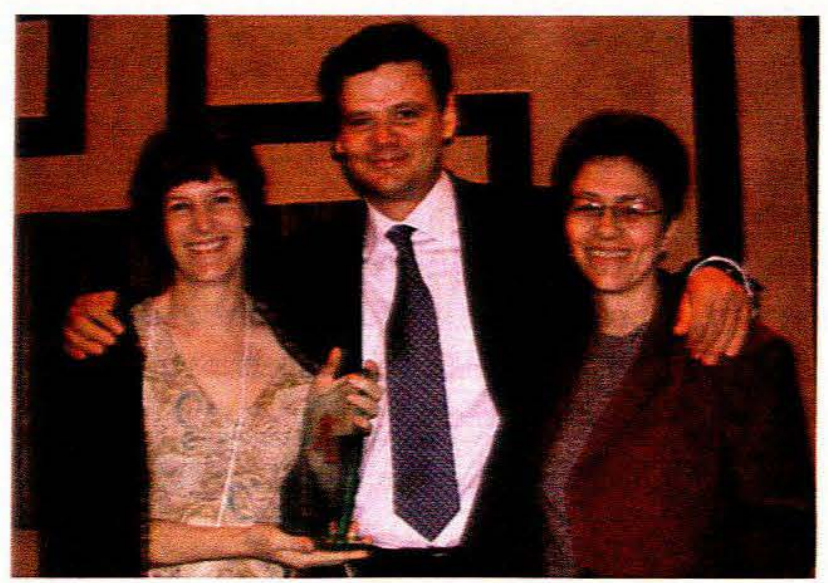

Ms Lies/ Gerntholz, representing the AIDS Law Project of South Africa (left), along with Raif Jürgens, Executive Director of the Canadian HIV/AIDS Legal Network, and Joanne Csete of Human Rights Watch (right).
Note:

The Awards for Action on HIV/AIDS and Human Rights are presented by the Canadian HIV/AIDS Legal Network and Human Rights Watch, and sponsored by the International Harm Reduction Development Program, the Hilda Mullen Foundation, and Mark Gallop.

The Canadian HIV/AIDS Legal Network (www.aidslaw.ca) is a national organisation engaged in education, legal and ethical analysis, and policy development, with over 250 organisational and individual members from across Canada and around the world. Founded in 1992, the Network promotes responses to HIV/AIDS that respect human rights; facilitates prevention efforts and access to care, treatment and support; minimises the adverse impact of HIV/AIDS on individuals and communities; and addresses the social and economic factors that increase vulnerability to HIV/AIDS and to human rights abuses. The Network is an NGO in Special Consultative Status with the United Nations Economic and Social Council and is a partner organisation of ALP of South Africa. Its work has received national and international recognition, and the United Nations Joint Program on HIVIAIDS has included the Network's activities in the UNAIDS collection of 'best practices:

Human Rights Watch (www.hrw.org) is an independent, non-governmental organisation that conducts regular, systematic investigations of human rights abuses in some 70 countries around the world. Its reputation for timely, reliable disclosures has made it an essential source of information for those concerned with human rights. Human Rights Watch addresses the human rights practices of governments of all political stripes, of all geopolitical alignments, and of all ethnic and religious persuasions. It defends freedom of thought and expression, due process and equal protection of the law, and a vigorous civil society; it documents and denounces abuses of internationally recognised human rights. Its goal is to hold governments accountable if they transgress the rights of their people. Human Rights Watch began in 1978, and today includes divisions covering Africa, the Americas, Asia and the Middle East as well as three thematic divisions on arms, children's rights, and women's rights, and special programmes on business and human rights and HIV/AIDS. The organisation maintains offices in New York, Washington, Los Angeles, London, Brussels, Moscow, and Tashkent. 
ALP has spearheaded communications efforts to inform the South African public of its rights with respect to HIVIAIDS. It has provided leadership on policy and legislation related to discrimination against people with AIDS, to protection of women and children from sexual violence, and to protection from mandatory HIV testing, among many other issues. It has also provided technical assistance on these and many other human rights issues to activists all over Africa.

'ALP's outstanding leadership addresses both the AIDS epidemic and the epidemic of human rights abuse that fuels AIDS in Africa, said Joanne Csete, director of the HIV/AIDS Programme at Human Rights Watch. 'ALP won't rest until people with AIDS in South Africa and those at risk can live in dignity.'

Dr Wan Yanhai, recipient of last year's international award (while being detained by the Chinese government), as well as Stephen Lewis, the UN Special Envoy for HIV/AIDS in Africa, participated in the awards ceremony in Montreal.

'South Africa has one of the worst HIV epidemics in the world,' said Mark Heywood, director of ALP. 'Unfortunately, the fact that having HIV also means suffering serial human rights violations is often overlooked. For a decade the AIDS Law Project, and more recently organisations such as TAC, have tried to change this. We have stood up for people's rights to employment, equality, education, dignity and treatment. Receiving this award means a great deal to us.'

ALP is part of the Centre for Applied Legal Studies at the University of Witwatersrand. For more information about ALP, visit

http://www.aidslaw.ca/Maincontent/awards.htm or www.alp.org.za/.

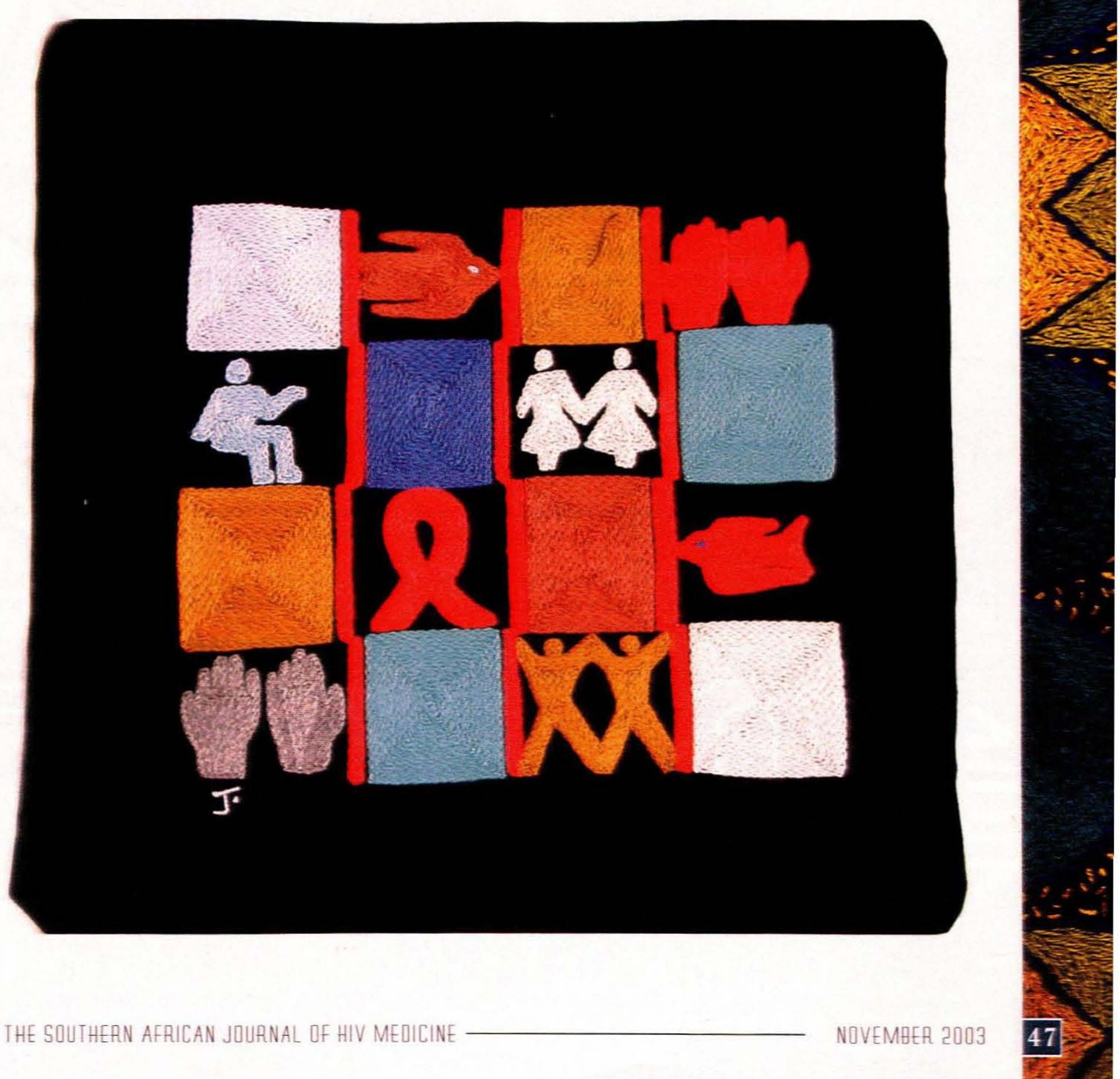

